\title{
Solving Exchange Rate Puzzles with \\ neither Sticky Prices nor Trade Costs
}

\author{
Michael J. Moore* \\ Queen's University Belfast, Northern Ireland \\ Maurice J. Roche \\ Ryerson University, Toronto, Canada
}

This version: $22^{\text {nd }}$ January 2009

\begin{abstract}
We present a simple framework in which both the exchange rates disconnect and forward bias puzzles are simultaneously resolved. The flexible-price two-country monetary model is extended to include a consumption externality with habit persistence. Habit persistence is modeled using Campbell Cochrane preferences with 'deep' habits. By deep habits, we mean habits defined over goods rather than countries. The model is simulated using the artificial economy methodology. It offers a neo-classical explanation of the Meese-Rogoff puzzle and mimics the failure of fundamentals to explain nominal exchange rates in a linear setting. Finally, the model naturally generates the negative slope in the standard forward market regression.
\end{abstract}

Keywords: Exchange Rate Puzzles; Forward Foreign Exchange; Habit Persistence

JEL classification: F31; F41; G12

*The address for correspondence is

Michael J. Moore,

School of Management and Economics,

Queen's University Belfast,

Belfast BT7 1NN, Northern Ireland.

Tel +44 (0) 28 90973208; Fax +44 (0) 28 90335156; email m.moore@qub.ac.uk

This paper was funded by the Irish Higher Education Authority's North-South Programme for

Collaborative Research. We are grateful to Martin Evans for his helpful comments. 


\section{Introduction.}

Obstfeld and Rogoff (2001) outlined an agenda for international macroeconomics centered on 'six puzzles'. The solution was to combine sticky prices and arbitrarily defined 'trade costs'. To us, this seems more like despair rather than a solution. This is not to deny that prices are not as volatile as some neo-classical models might suggest. Nor is it to deny the importance of trade costs as evidenced in the survey by Anderson and Van Wincoop (2004). However, both price volatility and trade costs are endogenous variables to be explained rather than assumed. The contention of this paper is that the flexible price monetary model is adaptable enough to at least explain those puzzles that concern nominal magnitudes. These are the exchange rate disconnect puzzle in its many manifestations and the seventh unmentioned puzzle - the forward bias problem ${ }^{1}$.

Our modelling strategy is to extend Campbell and Cochrane (1999) preferences to both a monetary and an international setting. With this specification there is an aggregate consumption externality (see for example Abel (1990) and Duesenberry (1949)) and utility is time-inseparable because of habit persistence. The utility function depends not only on the consumption of domestic and foreign endowments but also on the surplus of consumption over externally generated volatile and persistent habits, in each good. This makes the marginal rate of substitution between domestic and foreign goods volatile enough to explain the variability in the terms of trade. The high volatility of nominal exchange rates follows since prices are pinned down by the modest volatility of the money stock. The high correlation between the terms of trade and nominal exchange rates also follows since variations in both have their common source in the 'surplus consumption ratio'. The disconnect between nominal exchange rates and the conventionally modelled fundamentals apparently arises because the persistence of surplus

\footnotetext{
${ }^{1}$ Engel (2001) added the forward bias puzzle in his comment on the Obstfeld-Rogoff paper.
} 
consumption is close to a unit root process. This is also why our model replicates the MeeseRogoff puzzle.

In the standard model, when the domestic interest rate is relatively low, the exchange rate is expected to appreciate. The forward bias in our model arises because the preference specification has two motives for savings. The first is the conventional desire to smooth consumption intertemporally. The less familiar motive is a precautionary savings effect, which is dominant in our calibration of the model. When times are relatively bad for the owner of the domestic endowment, the surplus consumption ratio for the domestic good is low in relation to that for the foreign good, the time-varying risk aversion measured in the domestic good is relatively high and the own interest rate is relatively low. Consequently the holder of the domestic bond does not need to be compensated by as much of an expected appreciation and indeed may be content with an expected depreciation. The latter case, which arises easily in our model, is why the forward bias occurs.

The plan of the paper is as follows. The next section discusses the related literature. In section 3 we present the stylised facts that we are trying to explain. The theoretical framework is laid out and illustrated by way of an example in section 4. Section 5 describes the calibration of the model while section 6 discusses the results. The final section makes some concluding remarks.

\section{Related literature.}

One of the striking features of the literature is that it is rare indeed for any paper to try to solve the exchange rate disconnect puzzle, terms of trade volatility and the forward bias problem at the same time. This is surprising because the need to explain the extent of nominal exchange 
rate volatility is common to all three. An exception to this is the review paper by Sarno (2005). He argues that that non-linear adjustment is the key to understanding all three. This is consonant with the view expressed here.

Evans and Lyons (2002) and Killeen, Lyons and Moore (2006) have presented one of the most radical ways of explaining the exchange rate disconnect problem. They draw inspiration from the finance microstructure literature and argue that spot returns are determined by foreign exchange order flow. Evans and Lyons (2005) have developed this approach inside a general equilibrium framework though they are silent on the forward bias problem.

It has already been mentioned that Obstfeld and Rogoff (2001) do not even consider the forward bias problem as a major puzzle. Chari, Kehoe and McGrattan (2002) show that with price stickiness for at least four quarters, very low levels of the intertemporal elasticity of substitution, a shock to money growth that is much larger than empirically observed and a high cross-country correlation in shocks to money growth, their international business cycle model produces simulated moments that broadly mimic the properties of real and nominal exchange rates. Rather surprisingly for a sticky price model, they find it difficult to match the lack of variability in the international price ratio. However, they do not approach the subject of the forward bias. In fact, Engel (1999) has shown that the new open economy macroeconomics has little to contribute on the forward bias problem.

Moore and Roche (2005, 2007) have already applied Campbell and Cochrane (1999) preferences to address some aspects of the exchange rate disconnect problem but do not consider the forward bias puzzle ${ }^{2}$. Verdelhan (2007) attempts to explain the forward bias puzzle using Campbell and Cochrane (1999) preferences in a non-monetary economy with trade costs. It is

\footnotetext{
${ }^{2}$ An earlier application of Campbell and Cochrane (1999) preferences to the forward bias problem by Moore and Roche (2002) was inconclusive. The present paper succeeds because it allows real interest rates to vary.
} 
difficult to interpret this because real interest rates cannot be observed so that it is not clear if there is a real analogue to the forward bias problem in the data. Obviously, the exchange rate disconnect problem and the relationship between the terms of trade and nominal exchange rates cannot be addressed in a non-monetary setting. We can show that the Verdelhan (2007) result can be obtained as a special case of our analysis.

The literature that studies the forward bias problem in isolation is vast and we can only touch on some of the more relevant recent developments here ${ }^{3}$. The first point is that recent research has suggested that the forward bias (or equivalently the uncovered interest parity puzzle) does not always occur ${ }^{4}$. Bansal and Dahlquist (2000) show that the UIP problem is a feature which arises between developed countries and is much less likely to arise between emerging and developed countries. Frankel and Poonawala (2004) find a similar result. Our model can account for this. Chinn and Meredith (2004) show that UIP is only violated for short maturity bonds between G7 countries. For longer maturity bonds, the negative coefficient does not arise and is closer to one than zero. Alexius (2001) finds a similar result. In our model, the violation of uncovered interest parity is a short-run problem.

In an affine setting, Backus, Foresi and Telmer (2001) show that it is not, in general, possible to solve the forward bias puzzle in a rational no arbitrage setting unless (1) interest rates can theoretically assume negative values or (2) domestic and foreign interest rates respond asymmetrically to multiple state variables. Our paper is very definitely in the former category but we find that the negative interest problem in our case is not empirically very serious ${ }^{5}$.

Alvarez, Atkinson and Kehoe (2005) explain the forward bias by permitting a time varying degree of asset market participation. They explain the forward bias; they match the

\footnotetext{
${ }^{3}$ The classic survey is Engel (1996). Sarno (2005) contains a good update.

${ }_{5}^{4}$ Chinn (2006) reviews those examples where UIP does hold.

${ }^{5}$ Full details are available on request.
} 
persistence of the forward premium and the lack of persistence of spot returns. The calibrated model displays a volatility of spot returns that is more than $60 \%$ higher and volatility of forward premium that is more than $60 \%$ lower than are observed in the data. They do not address the exchange rate disconnect puzzle at all. From our reading of the model, we suspect that the implications for the volatilities of prices and the terms of trade may be counterfactual. The price ratio is likely to be too volatile and negatively correlated with nominal exchange rates leaving the terms of trade volatility too low.

Gourinchas and Tornell (2004) find that the forward bias problem can be explained by using 'distorted beliefs' about interest rate processes. Fisher (2006) also explains the bias using heterogeneous prior beliefs. Bachetta and Van Wincoop (2005) find that the forward bias arises due to rational expectation errors. These arise because some investors are constrained by information processing costs. The fraction of "rationally inattentive" investors varies endogenously. In a related paper, Carlson and Osler (2005) introduce a mixture of financial agents and commercial agents. Commercial agents have a demand for foreign exchange that is driven by good markets conditions only. The breakdown between the two types of agents is endogenous. They successfully replicate the forward bias puzzle. The strength of our approach is its simplicity: all agents are rational and have rational expectations at all times.

\section{The stylised facts.}

We model many exchange rate puzzles in this paper. For ease of digestion we split them into four groups (1) "exchange rate disconnect" facts, (2) volatility and persistence of the terms of trade and nominal exchange rates, (3) relative volatility and persistence of spot and forward exchange rates and (4) forward rate unbiasedness. 
Our first group of facts relate to exchange rate disconnect puzzles. Many economists have found it difficult to explain why the random walk exchange rate model outperforms many other models in short horizon forecasting (see Meese and Rogoff (1983)). Typically the root mean squared forecast error (RMSE) is estimated for both the monetary and random walk forecasting models and their ratio is calculated. The ratio of the RMSE of the monetary model to the driftless random walk model tends to be greater than unity at most forecast horizons. Mark (1995) and Faust, Rogers and Wright (2003) estimate the following exchange rate equation at forecast horizon $k$

$$
s_{t+k}-s_{t}=\alpha_{k}+\beta_{k} z_{t}+e_{t} \quad e_{t} \sim \operatorname{iid}\left(0, \sigma_{e}^{2}\right),
$$

where $z_{t}$ is the $\log$ deviation of the nominal spot exchange rate, $s_{t}$, from linearly formulated fundamentals predicted by the "monetary model" and is given by

$$
z_{t}=-\left(y_{t}^{1}-y_{t}^{2}\right)+\left(m_{t}^{1}-m_{t}^{2}\right)-s_{t}
$$

where $y_{t}^{j}$ and $m_{t}^{j}$ are the logarithm of real output and the nominal money supply for country $j$ respectively. In these studies they compute recursive out of sample forecasting exercises and produce forecasts for horizons 1, 4, 8, 12 and 16 quarters. Using real time data Faust, Rogers and Wright (2003) show that the relative RMSE was greater than unity and increasing with the forecast horizon for three out the four US dollar exchange rates studied ${ }^{6}$. They found that the average relative RMSE was 1.00 for the 1-quarter forecast horizon and increased to 1.50 for the 16 -

\footnotetext{
${ }^{6}$ Famously, Mark (1995) finds that as the forecast horizon increases, the Meese-Rogoff problem declines in severity and that the monetary model beats the random walk model. Faust, Rogers and Wright (2003) challenge this result in the following terms: "Had Mark (1995) constructed his dataset at almost any other time than early 1992, he would have found much less evidence of predictability. There is only a 2-year window around Mark's vintage in which the monetary model beats the random walk for both the DM and yen. That results like this arise from time to time is perhaps not surprising in an area where many researchers independently fit many models to each successive vintage. Only significant results are published. This sort of process seems likely to raise familiar data-mining problems"
} 
quarter forecast horizon (see Table 1). In a related set of facts many have estimated relationships such as

$$
s_{t}=\alpha_{0}+\alpha_{1}\left(y_{t}^{1}-y_{t}^{2}\right)+\alpha_{2}\left(m_{t}^{1}-m_{t}^{2}\right)+e_{t} \quad e_{t} \sim i i d\left(0, \sigma_{e}^{2}\right) .
$$

Numerous writers have pointed out how difficult it is to obtain cointegration from equations such as (3) or to even obtain sensible estimates of its parameters. There is a good survey of such work included in Taylor (1995).

The second set of facts that we consider concerns the volatility and persistence of exchange rates between the United States and other countries. Many studies have reported these facts for business cycle or high frequencies. For example Chari, Kehoe and McGrattan (2002) use quarterly Hodrick-Prescott filtered data that cover the floating period 1973:1 to 1998:4 for many European countries. They show that most of the fluctuations in the real exchange rate are accounted for by the traded goods real exchange rate. They report that the traded goods and all goods real exchange rates and nominal exchange rates are volatile ${ }^{7}$, persistent and highly correlated with each other. For example in Table 2 of Chari, Kehoe and McGrattan (2002) they report that the standard deviation of the traded goods real exchange rate (the terms of trade in our model) and nominal exchange rate are between $6.34 \%-8.72 \%$, the first order autocorrelation coefficient of the two exchange rates are between $0.79-0.86$ and the correlation coefficient between the two exchange rates between 0.94-0.99.

For simplicity, we do not model non-traded goods in this paper, so that we do not comment on the properties of the real exchange rate as measured by the internal terms of trade. We also assume perfect international risk sharing: this implies that the relative price of the consumption basket in each country is a constant when expressed in a common currency.

\footnotetext{
${ }^{7}$ Chari, Kehoe and McGrattan (2002) find that exchange rates are almost five times more volatile than output.
} 
However, we can consider variations in the external terms of trade. Obstfeld and Rogoff (2000) report the relevant facts for first differenced exchange rates using monthly data for most of the G7 countries. In their Table 2 they find that the correlation coefficient between the change in the nominal exchange rate and the change in the general terms of trade for 15 bilateral pairs is in the 0.51-0.90 range. They also find that both series are equally variable.

Many authors have presented the third set of stylized facts: those for spot and forward exchange rates ${ }^{8}$. As a reminder we present some statistics, using quarterly data, in Table 2. Like previous authors, we find that the standard deviation of the forward discount is smaller than that of expected forward speculative profit and is an order of magnitude less than that of the spot return. The second is that the AR(1) coefficient of the spot return is close to zero while the forward discount is very persistent.

The final set of facts focuses on the forward bias problem directly. The coefficient on the forward discount from a regression for predicting spot return in the following regression

$$
s_{t+1}-s_{t}=a_{1}+b_{1}\left(f_{t}-s_{t}\right)+u_{t+1}
$$

is reported by many researchers to have a negative sign (see the references in the last footnote). In (4) $f_{t}$ is the log of the one period forward exchange rate. In Table 4 we present the fact, that for all major developed countries, the estimate of the coefficient $b_{1}$ is negative rather than the unity suggested by a simple understanding of the rational expectations efficient markets hypothesis. Since covered interest rate parity holds (4) can be interpreted as an uncovered interest rate parity regression equation. The two necessary Fama conditions for a negative $b_{1}$ are that the covariance between the expected forward speculative profit and the expected spot return

\footnotetext{
${ }^{8}$ See Hodrick (1987), Backus, Gregory and Telmer (1993) and Bekaert (1996) for example.
} 
is negative and that the variance of expected forward speculative profit exceeds the variance of the expected spot return. The evidence supporting these facts is also presented in Table 2 .

\section{The model.}

\subsection{The basic framework}

The structure of the model is a version of the well-known Lucas (1982) two-country, two-good, two-money representative agent story. The addilog utility function ${ }^{9}$ to be maximized by the domestic representative agent is:

$$
E_{t}\left(\sum_{t=0}^{\infty} \beta^{t}\left\{\frac{\left(C_{t}^{1}-H_{t}^{1}\right)^{(1-\gamma)}}{1-\gamma}+\frac{\left(C_{t}^{2}-H_{t}^{2}\right)^{(1-\gamma)}}{1-\gamma}\right\}\right)
$$

subject to the equation of motion for wealth $W_{t}$ :

$$
W_{t+1}=S_{t+1} \sum_{\tau_{t+1} \in \mathrm{T}} A^{2}\left(\tau_{t+1}\right)+\sum_{\tau_{t+1} \in \mathrm{T}} A^{1}\left(\tau_{t+1}\right)+P_{t}^{1} Y_{t}^{1}
$$

and the wealth constraint:

$$
W_{t}=P_{t}^{1} C_{t}^{1}+S_{t} P_{t}^{2} C_{t}^{2}+\sum_{\tau_{t+1} \in \mathrm{T}} Q^{1}\left(\tau_{t+1}, \tau_{t}\right) A^{1}\left(\tau_{t+1}\right)+S_{t} \sum_{\tau_{t+1} \in \mathrm{T}} Q^{2}\left(\tau_{t+1}, \tau_{t}\right) A^{2}\left(\tau_{t+1}\right)
$$

The assumption of addilog preferences have been extensively used in the literature for decades (for example see Ait-Sahalia et al (2004) and Backus (1993)). Households consume home and foreign goods and purchase state contingent nominal bonds $A^{1}\left(\tau_{t+1}\right)$, each of which pays off one

\footnotetext{
${ }^{9}$ The superscript denotes country of origin of the good. Uppercase letters denote variables in levels; lowercase letters denote variables in log levels, including growth and interest rates. Greek letters without time subscripts denote parameters. Bars over variables denote steady states. We assume that the parameters in the model are identical for both countries. This is not essential to the model but we have not found it necessary to emphasize cross-country parameter differences. Because of this and for simplicity of exposition, we present the problem for the home country (country 1 ) representative agent only. Country 2 is the foreign country.
} 
unit of home currency in state $\tau_{t+1}$ and $A^{2}\left(\tau_{t+1}\right)$, each of which pays off one unit of foreign currency in state $\tau_{t+1} . \mathrm{T}$ is the set of all possible states.

In (5) $\beta$ is the discount factor, $\gamma$ is a curvature parameter, $C_{t}^{j}$ is consumption of goods and services of country $j$ and $H_{t}^{j}$ is the subsistence consumption (or habit) of goods and services of country $j$. Note that, if $H_{t}^{j}$ is set to zero then (5) collapses to standard addilog preferences with no habit. We assume that $H_{t}^{j} \quad j=1,2$ is the same for both countries: this highlights a feature of our modelling strategy, that habits are goods rather than country specific. Ravn, Schmitt-Grohe, and Uribe (2006, 2007) argue that the case for modelling habit formation at the level of individual goods, as we have, is at least as compelling as the traditional approach of modelling habits as an aggregate phenomenon only. They refer to this preference specification as 'deep habit formation'. Their analysis concerns the cyclical behaviour of markups but they show that the demand side of the macro economy is indistinguishable from that pertaining to an environment in which agents have traditional or what they call 'superficial' habits. In (6) and (7) $W_{t+1}$ is wealth next period in country, $S_{t}$ is the level of the spot exchange rate, $P_{t}^{j}$ is the price of good $j, Y_{t}^{1}$ is the endowment in country 1 and $Q^{j}\left(\tau_{t+1}, \tau_{t}\right) i=1,2$ is the nominal bond price in the currency of country $j$ of state $\tau_{t+1}$ bonds.

Habit persistence takes the form of an aggregate consumption externality i.e. "Keeping up with the Jones's" effects along the lines of Duesenberry (1949) and Abel (1990). Empirical results from the economics of happiness literature suggests that relative income is an important factor in individuals' levels of satisfaction; see for example Oswald and Clarke (1996) and Oswald (1997). Chetty and Szeidl (2004) provide a compelling non-psychological argument for an aggregate habit externality. In their model, habit-like behaviour can arise from the rigidities 
inherent in the consumption of "commitment goods". These are goods the consumption of which often cannot be changed in the short run. Aggregating an economy of heterogeneous households with standard, non-habit preferences over such commitment goods yields aggregate dynamics that coincide precisely with the representative consumer economy of Constantinides (1990) with the exception that habit formation is external as we assume in this paper.

We assume the usual cash in advance constraint:

$$
\frac{M_{t}^{j}}{P_{t}^{j}}=C_{t}^{j}, \quad j=1,2
$$

where $M_{t}^{j}$ is the a quantity of the currency of country $j$. It is easy to model money as part of the utility function. Feenstra (1986) shows that the cash-in-advance framework is a special case of money-in-the utility function where the real balance component of utility takes the Leontief form. It is encouraging to report that the results in this paper only require the simplest possible monetary specification.

We assume an external habit specification. We define:

$$
X_{t}^{j}=\frac{\bar{C}_{t}^{j}-H_{t}^{j}}{\bar{C}_{t}^{j}}, \quad j=1,2
$$

where $\bar{C}_{t}^{j}$ is aggregate consumption per capita of goods and services of country $j$ rather than individual consumption: it does not affect individual choice at the margin and $X_{t}^{j}$ is the surplus consumption ratio. Identical individuals choose the same level of consumption in equilibrium, so $C_{t}^{j}=\bar{C}_{t}^{j}$. Like Lucas (1982) there is perfect international risk pooling in equilibrium ${ }^{10}$. This is a result of our assumption that households can purchase state contingent nominal bonds as in Chari, Kehoe and McGrattan (2002). Under this assumption, consumption of each good equals

\footnotetext{
${ }^{10}$ Recent work by Brandt, Cochrane and Santa-Clara (2006) suggests that international risk sharing is very high.
} 
half of the current endowment and in the remainder of the paper we will use consumption and endowment interchangeably. ${ }^{11}$

The log of the surplus consumption ratio for good $j$ evolve as follows:

$$
x_{t+1}^{j}=(1-\phi) \bar{x}+\phi x_{t}^{j}+\lambda\left(x_{t}^{j}\right)\left(v_{t+1}^{j}\right), \quad j=1,2,
$$

where $\phi<1$, is the habit persistence parameter, $\bar{x}$ is the steady state value for the logarithm of the surplus consumption ratio which we define below in equation (12) and $v_{t+1}^{j}$ is the shock to endowment growth. The function $\lambda\left(x_{t}^{j}\right)$ describes the sensitivity of the log surplus consumption ratio of good $j$ to endowment innovations of good $j$. It depends non-linearly on the current $\log$ surplus consumption ratio:

$$
\begin{aligned}
\lambda\left(x_{t}^{j}\right) & =\frac{\sqrt{1-2\left(x_{t}^{j}-\bar{x}\right)}}{\bar{X}}-1 & & \text { for } x_{t}^{j} \leq x_{\max } \quad j=1,2, \\
& =0 & & \text { for } x_{t}^{j}>x_{\max } \\
\text { where } x_{\max } & =\bar{x}+\frac{1-\bar{X}^{2}}{2} . & &
\end{aligned}
$$

where $\bar{X}$ is the steady state value of the surplus consumption ratio and is defined as:

$$
\bar{X}=\frac{\gamma \sigma_{v}}{\sqrt{\gamma(1-\phi)-\delta}}
$$

where $\gamma(1-\phi)>\delta$. This is an alternative given in Campbell and Cochrane (1999), which allows for some variation in real interest rates. Specifically, they show that the parameter $\delta$ monitors the sensitivity of real interest rates to the surplus consumption ratio:

$$
i_{t}^{r}=\bar{i}^{r}-\delta\left(x_{t}-\bar{x}\right)
$$

where $i_{t}^{r}$ is the real rate of interest and $\bar{i}^{r}$ is its steady state value ${ }^{12}$. The local curvature of the utility function with respect to good $j$ is:

\footnotetext{
${ }^{11}$ The solution to the optimization problem is laid out in appendix (A1).
} 


$$
\frac{\gamma}{X_{t}^{j}}=-C_{t}^{j} \frac{U_{c c}\left(C_{t}^{j}, H_{t}^{j}\right)}{U_{c}\left(C_{t}^{j}, H_{t}^{j}\right)} \quad j=1,2
$$

At the steady state, it is easy to show that (14) is:

$$
\frac{\gamma}{\bar{X}}=\frac{\sqrt{\gamma(1-\phi)-\delta}}{\sigma_{v}}
$$

This expression is positively related to the coefficient of relative risk aversion for the one good case $^{13}$. For convenience, we will refer to (14) as the own-good risk aversion.

Though there is no difficulty in doing so, forward contracts are not modelled explicitly because all a proper modelling would lead to is covered interest parity. So we simply assume the latter and define the forward rate as:

$$
F_{t}=\frac{q_{t}^{2} S_{t}}{q_{t}^{1}}
$$

where $q_{t}^{1}$ and $q_{t}^{2}$ are the risk-free nominal bond prices in home and foreign currency prices respectively. ${ }^{14}$

\subsection{A worked example}

The easiest way to illustrate the potential of the model is to make specific assumptions about the underlying stochastic processes and to follow through the implications. We assume that output or endowment growth and money growth follow simple AR(1) processes:

$$
\Delta y_{t+1}^{j}=\left(1-\rho_{\mu}\right) \bar{\mu}+\rho_{\mu} \Delta y_{t}^{j}+v_{t+1}^{j}, \quad v_{t+1}^{j} \sim N\left(0, \sigma_{v}^{2}\right), \quad j=1,2
$$

and

\footnotetext{
12 For further details see equation (A13) and the discussion that follows it in Appendix (A3).

${ }^{13}$ Defining risk aversion in a multi-good model is not trivial (see Engel, 1992 and Moore, 1997). An intertemporal model has as many goods as time periods. In addition, our model has two goods in each time period. We evade this problem because we assume below that the home and foreign endowment shock variances are the same.
}

${ }^{14}$ See the definitions in equations (A2) and (A3) in Appendix A1. 


$$
\Delta m_{t+1}^{j}=\left(1-\rho_{\pi}\right) \bar{\pi}+\rho_{\pi} \Delta m_{t}^{j}+u_{t+1}^{j}, \quad u_{t+1}^{j} \sim N\left(0, \sigma_{u}^{2}\right), \quad j=1,2
$$

respectively. The unconditional means of endowment and money growth are defined as $\bar{\mu}$ and $\bar{\pi}$ respectively. The variances of shocks to endowment and money growth are defined as $\sigma_{v}^{2}$ and $\sigma_{u}^{2}$ respectively. We also assume that the shocks to endowment and money growth are uncorrelated $^{15}$.

\subsubsection{Volatility of the terms of trade and nominal exchange rates}

From equations (A1) and (A4) in Appendix (A1), the log of the terms of trade and nominal exchange rates are:

$$
\begin{gathered}
r_{t}=\gamma\left(y_{t}^{1}-y_{t}^{2}\right)+\gamma\left(x_{t}^{1}-x_{t}^{2}\right) \\
s_{t}=-(1-\gamma)\left(y_{t}^{1}-y_{t}^{2}\right)+\gamma\left(x_{t}^{1}-x_{t}^{2}\right)+\left(m_{t}^{1}-m_{t}^{2}\right)
\end{gathered}
$$

respectively. The only way that equations (19) and (20) differ from standard addilog preferences are in the terms in $\left(x_{t}^{1}-x_{t}^{2}\right)$. This is the difference in the surplus consumption ratios between domestic and foreign goods. Moore and Roche $(2002,2005)$ also show that the cross-good difference in the log surplus consumption ratio is very volatile in comparison to the other terms in (19) and (20), the so-called real and nominal fundamentals. From Appendix (A2), the variance of spot returns is:

$$
\operatorname{Var}\left(s_{t+1}-s_{t}\right)=2\left(\frac{\sigma_{u}^{2}}{1-\rho_{\pi}^{2}}+(1-\phi)^{2} \gamma^{2} \sigma_{x}^{2}+\sigma_{v}^{2}\left(1-\frac{\gamma}{\bar{X}}\right)^{2}\right)
$$

When the variance of the surplus consumption ratio, $\sigma_{x}^{2}$, is large, it dominates the expression in equation (21). Similarly, the variance of the terms of trade changes is:

\footnotetext{
${ }^{15}$ For what follows, we also set the persistence of real shocks to zero (as is often found for the growth rate in seasonally adjusted U.S. real consumption of non-durables and services per capita).
} 


$$
\operatorname{Var}\left(r_{t+1}-r_{t}\right)=2\left((1-\phi)^{2} \gamma^{2} \sigma_{x}^{2}+\sigma_{v}^{2}\left(\frac{\gamma}{\bar{X}}\right)^{2}\right)
$$

Again sufficiently large $\sigma_{x}^{2}$ can dominate (22) and render the volatility of the terms of trade changes comparable to the volatility of the nominal exchange rate. Finally, in the standard addilog model, the correlation coefficient between the terms of trade and nominal exchange rate changes is determined by whether the curvature parameter $\gamma$ is greater than or less than unity. In our model, the main feature governing this correlation is the relative importance of surplus consumption in equations (19) and (20).

\subsubsection{Exchange Rate Disconnect Puzzle}

It is not hard to see whence the exchange rate disconnect problem comes. The volatilities of the terms of trade and nominal exchange rates are dominated by the volatility of the surplus consumption ratio. It is also easy to see from equation (10) that that the persistence of the surplus consumption ratio is governed by the parameter $\phi$ which Campbell and Cochrane (1999) argue should be close to unity. This is what drives the Meese and Rogoff (1983) puzzle because omitting the unobservable but volatile surplus consumption ratio from equations such as (1) makes forecasting very imprecise. We can also see why attempts to find cointegration in equation (3) have apparently led to many rejections of the monetary model. The presence of near-unit root processes in (19) and (20) reduces the power of the cointegration tests. It also reduces the power of tests of estimates of the parameters (see Elliot (1998)). 


\subsubsection{Forward Bias Puzzle}

It is straightforward to explain how the forward bias actually arises. From Appendix (A3), equation (A16), it is clear that the nominal interest rate on country $j$ 's bonds at time $t$ is:

$$
i_{t}^{j}=\alpha+\rho_{\pi} \Delta m_{t}^{j}+\theta\left(x_{t}^{j}-\bar{x}^{j}\right)
$$

where the constants $\alpha$ and $\theta$ are defined in equations (A17) and (A18) respectively. Variations in nominal rates are determined by monetary factors and a real term that is a multiple of the deviation of the surplus consumption ratio from its mean. In general, $\theta$ can take any sign. When it is zero, the precautionary savings motive is exactly offset by the normal intertemporal substitution motive for savings. This means that nominal interest rates are determined by the Fisher Open Condition. We will show below that uncovered interest parity also holds in this case. However, the interesting case occurs when $\theta$ is positive. In this case the precautionary savings motive dominates the intertemporal substitution effect. When the surplus consumption ratio in the domestic good is low, risk aversion in terms of the domestic good is high, agents need little incentive to hold domestic bonds and the domestic nominal interest rate is low. If this effect is strong enough, (i.e. $\theta$ is sufficiently positive), agents do not need to be compensated for low yields by an expected currency appreciation and may even be prepared to accept an expected depreciation. This is the forward bias problem in a nutshell.

Obviously, the forward bias problem means that the coefficient $b_{1}$ in equation (4) must be negative. Fama's first necessary condition for this result concerns the covariance between expected forward profits and the expected spot return. From Appendix (A4), this is

$$
\operatorname{Cov}\left[\left(f_{t}-E_{t}\left(s_{t+1}\right),\left(E_{t}\left(s_{t+1}-s_{t}\right)\right)\right)\right]=-2 \gamma(1-\phi)(\gamma(1-\phi)+\theta) \sigma_{x}^{2}
$$


It is shown in Appendix $(A 3)$ that $\gamma(1-\phi)+\theta$ is positive so long as risk aversion exceeds unity. Consequently, the covariance in (24) is always negative, meeting Fama's condition.

Fama's second necessary condition for a negative $b_{1}$ is that the variance of the expected forward profit (equation (A24)) is greater than the variance of the expected spot return (equation (A22)). The ratio of the two variances is:

$$
\frac{\operatorname{Var}\left(f_{t}-E_{t} s_{t+1}\right)}{\operatorname{Var}\left(E_{t}\left(s_{t+1}-s_{t}\right)\right)}=\frac{(\gamma(1-\phi)+\theta)^{2} \sigma_{x}^{2}}{\frac{\rho_{\pi}^{2} \sigma_{u}^{2}}{1-\rho_{\pi}^{2}}+\gamma^{2}(1-\phi)^{2} \sigma_{x}^{2}}
$$

The higher $\theta$, the more likely that Fama's condition holds. By contrast, the higher the conditional variance of money growth, $\frac{\rho_{\pi}^{2} \sigma_{u}^{2}}{1-\rho_{\pi}^{2}}$, the more likely $b_{1}$ is positive. The latter is most plausible in countries which have unsophisticated institutions and are prone to hyperinflation.

The slope coefficient $b_{1}$ is derived in Appendix (A4) as equation (A26). It is repeated here for convenience:

$$
b_{1}=\frac{\frac{\rho_{\pi}^{2} \sigma_{u}^{2}}{1-\rho_{\pi}^{2}}-\gamma(1-\phi) \theta \sigma_{x}^{2}}{\frac{\rho_{\pi}^{2} \sigma_{u}^{2}}{1-\rho_{\pi}^{2}}+\theta^{2} \sigma_{x}^{2}}
$$

The sign is ambiguous. If $\theta=0$, the slope is unity and UIP holds. A necessary condition for a negative $b_{1}$ is that $\theta>0$. In the case where the persistence of money growth shocks $\rho_{\pi}$ is zero, the slope simplifies to:

$$
\frac{-\gamma(1-\phi)}{\theta}
$$


In this case, $\theta>0$ is necessary and sufficient for a negative slope ${ }^{16}$. More generally, the slope is most likely to be negative the less important are monetary factors. If the conditional variance of money growth is sufficiently high, then a positive slope will be obtained even if $\theta>0$. This explains why UIP is more likely to hold when developing countries are considered as reported in Bansal and Dalquist (2000).

\section{Calibration}

We choose some of the parameters in the model by estimating them using data from the United States. Other parameter values are taken from the literature. The remaining parameters are chosen so that that the steady state surplus consumption ratio is approximately $5 \%$ as in Campbell and Cochrane (1999) and that local risk aversion is no more than 10. We believe that the level of local risk aversion of 35, in Campbell and Cochrane (1999), is too high.

We need to choose time series data to proxy for endowments and money. We follow Campbell and Cochrane (1999) who use seasonally adjusted real consumption expenditure on non-durables and services per capita to proxy for endowments in the United States. The following parameters for consumption growth rates are taken from Campbell and Cochrane (1999). The unconditional mean $\bar{\mu}$ is set equal to $0.4725 \%$ per quarter. The $\operatorname{AR}(1)$ coefficient of consumption growth $\rho_{\mu}$ is set to zero. The standard deviation of shocks to consumption $\sigma_{v}$ is set to $0.75 \%$ per quarter.

Typically either the base money or M1 is used for the money stock. We follow Christiano (1991) who used base money in a closed economy model with a cash-in-advance

\footnotetext{
${ }^{16}$ This is the slope that Verdelhan (2007) reports. To obtain this, he had to assume substantial trade costs: our 'deep habits' approach makes this unnecessary. In addition, it is difficult to see how Verdelhan can be generalized to a monetary setting. This is necessary to address the full range of puzzles considered in this paper.
} 
constraint. The parameters of money per capita growth rates are estimated using an AR(1) process. The base money data for the U.S. are quarterly and available for the period 1959:12005:4 from the Federal Reserve Bank of St. Louis database. The unconditional mean of money growth per capita $\bar{\pi}$ is estimated to be $1.36 \%$ per quarter. The $\operatorname{AR}(1)$ coefficient of money growth per capita is estimated to be 0.20 with a t-statistic based on Newey-West standard errors of 1.57. Thus at conventional significance levels one cannot reject the null hypothesis that $\rho_{\pi}$ is zero. In the baseline parameterization we set these to $\rho_{\pi}$ to 0.1 , which is within the estimated 95\% confidence interval. In sensitivity analysis we also set $\rho_{\pi}$ to zero. The standard deviation of shocks to money growth $\sigma_{u}$ is estimated to be $0.946 \%$ per quarter.

There are four more parameters to choose. These are the discount factor $\beta$, the sensitivity of the real interest rate to the surplus consumption ratio $\delta$, the $\operatorname{AR}(1)$ coefficient of the log of the surplus consumption ratio $\phi$, and the power parameter in the utility function $\gamma$. Since we are going to simulate a quarterly artificial economy we choose $\beta=0.99$, a value commonly used in the literature. The parameter $\delta$ has to be negative for the precautionary savings motive to dominate the intertemporal substitution savings motive for savings. In the baseline parameterization we set $\delta=$ -.005 . For our sensitivity analysis we also set $\delta=-.0025$.

We choose $\gamma$ and $\phi$ so that the surplus consumption ratio is approximately $5 \%$ and that the value of local risk aversion is no more than 10 . The parameter $1 / \gamma$ is the elasticity of substitution between domestic and foreign goods. Chari, Kehoe and McGrattan (2002) use $1 / \gamma=1.5$ and Backus, Kehoe and Kydland (1994) also use $1 / \gamma=1.5$. The parameter $1 / \gamma$ is also the elasticity of intertemporal substitution. Gourinchas and Parker (2002) estimate $1 / \gamma \approx 2$ using US data. Crossley and Low (2008) estimate $1 / \gamma \approx 2$ using UK data. Thus we choose $1 / \gamma=2$ as a baseline 
parameter. Campbell and Cochrane (1999) choose $\phi$ to match the first order serial correlation coefficient of the log price-dividend ratio. We estimate this parameter using US stock market data from Robert Shiller's website and choose $\phi$ to be 0.999 . This value is a little higher than that reported in Campbell and Cochrane (1999) as our sample period to 2004 and the price-dividend ratio became more persistent as a result of the boom in the US economy over this period.

Thus in the baseline parameterization we set $\gamma=0.5$ and $\phi=0.999$. For our sensitivity analysis we also set $\phi=0.995$ and $\gamma=0.7$ (a value used to match the Sharpe ratio in Campbell and Cochrane (1999) and its reciprocal is close to the value used for the elasticity of substitution between domestic and foreign goods in Chari, Kehoe and McGrattan (2002) and Backus, Kehoe and Kydland (1994) ). The baseline parameterization is summarized in Table 5.

\section{Results}

We simulated the model 1000 times generating 132 observations for each series. The results for the moments of interest are presented in Tables 4-8. Where appropriate we present the mean of the simulated moment and its standard error (in parenthesis). In Table 4 we present the relative RMSE of the monetary model in out-of-sample forecasting in the theoretical economy. The nominal exchange rate is generated using equation (20). We follow Faust et al's (2003) choice of the conventional nominal exchange rate fundamentals in the forecasting exercise, namely the cross-country money and output differentials as in equations (1) and (2). Thus in this experiment we are examining the effect on the relative RMSE of omitting the crossgood difference in the log surplus consumption ratio in the conventional nominal exchange rate fundamentals. It is evident from the second column in Table 4 that the relative RMSE is greater than unity and increases with the forecast horizon, just as in the data. Thus our model is capable 
of producing the general result from Meese and Rogoff (1983). Our suggestion is that this is due to the fact that an important real variable is omitted from the nominal exchange rate fundamentals, namely the cross-good difference in the log surplus consumption ratio. These results do not change very much when we perform sensitivity analysis reported in columns 3-6 in Table 4.

The exchange rate disconnect puzzle also manifests itself in the cointegration literature with the common finding that the nominal exchange rate does not appear to be linearly cointegrated with the fundamentals from the monetary model. Omitting the cross-good difference in the log surplus consumption ratio from the fundamentals may cause this result. In order to investigate this we conducted two simple experiments. In each we followed Mark (1995) and Faust et al. (2003) and linearly use the cross-country money and output differentials as fundamentals for the nominal exchange rate. In the first experiment we assume that the cointegrating vector is plus unity on the cross-country money differential and minus unity on the cross-country output differential. The residual $z_{t}$ is tested for a unit root (no cointegration) using an augmented Dickey-Fuller test where the lag length in the test regression is chosen by reduction methods. The null hypothesis of no cointegration between the nominal exchange rate and crosscountry money and output differentials is only rejected $20.7 \%$ (see Table 5) of the time despite the fact that they are cointegrated by construction in the model.

In the second experiment we estimate a linear relation relationship (3) by FM-OLS. The residual $\hat{e}_{t}$ is tested for a unit root. The null hypothesis of no cointegration between the nominal exchange rate and cross-country money and output differentials is rejected $45.4 \%$ of the time. We also conduct a Wald test of the joint null hypothesis $\mathrm{H}_{0}: \alpha_{1}=\gamma-1$ and $\alpha_{2}=1$ in equation (3). The null is rejected in $71.8 \%$ of the 1,000 replications. This result is commonly found in the data 
(see Taylor (1995)). The main reason for our results is that a very volatile and near integrated variable is omitted from the cointegrating relationship. These results are not very sensitive to the values of $\phi, \gamma$ and $\delta$.

A final way our model throws light on the exchange rate disconnect puzzle is the fact that some researchers have suggested that the volatility of the fundamentals is not enough to produce the volatility in the nominal exchange rate (see for example Flood and Rose (1999)). We disagree. In the model the standard deviation of the Hodrick-Prescott filtered and firstdifferenced logged nominal exchange rate is $7.98 \%$ and $6.36 \%$ respectively. These results are presented in column 2 of Tables 6 and 7 respectively. These are similar in magnitude to what is found in the data. The standard deviation of the nominal exchange rate is higher if we increase $\gamma$, make $\delta$ larger in absolute terms, or lower $\phi$ (see sensitivity analysis reported in columns 3-6 in Tables 6 and 7).

Our model produces the near zero persistence in the first differenced nominal exchange rate. The persistence of the Hodrick-Prescott filtered nominal exchange rate and terms of trade is a little lower in the model than is found in the data. The latter result is similar to that produced by the model of Chari, Kehoe and McGrattan (2002). Our model produces a lower correlation between the terms of trade and nominal exchange rate than is typically found in the data with the baseline parameterization.

The final set of results we report are about the forward rate unbiasedness puzzle and related forward market puzzles. The results are in Table 8. The estimate of the slope coefficient from regressing the spot change on the forward premium is -1.08 . This is approximately the average value we found in the data (see Table 2). The ranking of the volatility of the spot change, the expected forward profit, the expected spot change and the forward premium are the 
same in the model as found in the data. As mentioned above the standard deviation of the spot change is $6.36 \%$, which similar to what is empirically observed. The standard deviation of the expected forward profit is $0.97 \%$, which is in the middle of the range of the estimates in Table 3 . The standard deviation of the forward premium is marginally lower than what we find in the data. In the model the $\mathrm{AR}(1)$ coefficient of the spot change is 0.02 which is consistent with what is empirically found. The $\mathrm{AR}(1)$ coefficient of the forward premium is 0.40 which is slightly lower than that found in the data.

\section{Conclusions}

This paper has proposed a modelling strategy that makes substantial progress towards resolving many of the outstanding exchange rate puzzles. A model that combines Campbell and Cochrane (1999) habit persistence defined over individual goods in a monetary framework is capable of explaining the disconnect between nominal exchange rates and conventionally formulated fundamentals, the forward bias puzzle, the Meese-Rogoff puzzle and of mimicking the volatilities of the terms of trade, nominal exchange rates, the forward premium, expected spot returns and expected forward profits.

The model, proposed here, still has limitations. As it stands, it does not explain the behaviour of real exchange rates. However it could be expanded to incorporate non-traded goods in each country. Boudoukh, Richardson and Whitelaw (2005) have demonstrated empirically that forward interest rates forecast future spot interest rates and inflation rates, and that differentials of these forward rates forecast movements in exchange rates. The model needs to be extended to explore that issue. It also only describes an exchange economy. Both Backus, Kehoe and Kydland (1992) and Chari, McGrattan and Kehoe (2002) model production 
economies. We need a very different model to intelligently assess the impact of Campbell and Cochrane (1999) habits on other business cycle properties. Ljungqvist and Uhlig (2000) have pointed out that there are problems in expanding their framework to a production economy. 'Consumption bunching' rather than consumption smoothing becomes welfare optimal. However, this only arises if the habit is internalised: our habit is strictly an externality. The model is explicitly concerned with floating exchange rate regimes. Moore and Roche (2005) suggest that it may even be able to explain the puzzle as to why the terms of trade were less volatile during the Bretton Woods period. Obstfeld and Rogoff (2001) see this as an example of the "Baxter-Stockman neutrality of exchange rate regime puzzle". There is a striking increase in the volatility of the cross-good difference of the log surplus consumption ratio between the fixed and floating rate periods. The corresponding change in the volatility of the 'fundamentals' is not nearly so noticeable, as Flood and Rose (1999) have already observed. It would appear that our model goes some distance to explaining the increase in volatility in the floating over the fixed rate period. In the microstructure literature, Hau (1998), Killeen, Lyons and Moore (2006) and Jeanne and Rose (2002) show how regime-dependent volatility can be explained by endogenous changes in the foreign exchange market microstructure. For these writers, an exchange rate regime change has real effects because it alters the real functioning of markets. They see the difference between a fixed and floating rate regime as being a real and not a monetary phenomenon. This is consistent with our outlook. However, the challenge for the microstructure approach to foreign exchange markets is to reconcile their results with macroeconomic general equilibrium analyses such as the one developed here. Evans and Lyons (2005) have made substantial progress down that road. 
The claims being made in this paper are very traditional. Rather than use contrivances such as sticky prices and arbitrarily set trade costs, we insist on accounting for exchange rate puzzles using an optimising framework. The desired results emanate from a carefully selected preference specification. Though we could have chosen even more general preferences, we did not need to. We invoke Occam's Razor to support our approach. 


\section{References}

Abel, Andrew. "Asset Prices Under Habit Formation and Catching Up with the Joneses."

A.E.R., Papers and Proceedings 80 (May 1990): 38-42.

Ait-Sahalia, Yacine, Parker, Jonathan A., and Yogo, Motohiro (2004). Luxury Goods and the Equity Premium. Journal of Finance 59, 2959-3008.

9, (August, 2001):505-517.

Alvarez, Fernando, Atkeson, Andrew, and Kehoe, Patrick J. “Time-Varying Risk, Interest Rates, and Exchange Rates in General Equilibrium.” Mimeo, Federal Reserve Bank of Minneapolis, Working Paper 627, (October 2005).

Anderson, James and Van Wincoop, Eric. "Trade Costs." Journal of Economic Literature 42, (September, 2004): 691-751.

Bachetta, Philippe and Van Wincoop, Eric. "Rational Inattention: A Solution to the Forward Discount Puzzle.” Mimeo, (2005).

Backus, Dave K., Kehoe, Patrick J. and Kydland, Finn E. "International Business Cycles. J. P. E. 100, (December 1992): 745-775.

Backus, Dave K., Gregory, Allan W., Telmer, Chris I. “Accounting for Forward Rates in Markets for Foreign Currency. Journal of Finance 58, (December 1993):1887-1908.

Backus, Dave K., Foresi, Silverio and Telmer, Chris I. "Affine Term Structure Models and the Forward Premium Anomaly.” Journal of Finance 56, (February 2001): 279-304.

Backus, David K., (1993). Interpreting Comovements in the Trade Balance and the Terms of Trade, Journal of International Economics 24, 375-387.

Backus, David K., Kehoe, Patrick J., and Kydland, Finn E. (1994). Dynamics of the Trade Balance and the Terms of Trade: The J-Curve? American Economic Review 84, 84-103. 
Alexius, Annika. "Uncovered Interest Parity Revisited." Review of International Economics

Bansal, Ravi and Dahlquist, Magnus. "The Forward Premium Puzzle: Different Tales from

Developed and Emerging Economies.” J. Internat. Econ. 51, (June 2000): 115-144.

Bekaert, Geert. "The Time-Variation of Risk and Return in Foreign Exchange Markets: a General Equilibrium Perspective.” Review of Financial Studies 9, (Summer, 1996): 427-440.

Boudoukh, Jacob, Richardson, Matthew and Whitelaw, Robert. "The Information in LongMaturity Forward Rates: Implications for Exchange Rates and the Forward Premium Anomaly", NBER working paper 11840, (December 2005).

Brandt, Michael W., Cochrane, John H. and Santa-Clara, Pedro "International Risk Sharing is Better Than You Think (or Exchange Rates Are Much Too Smooth)." J. Monetary Econ., article in press (April 2006).

Campbell, John Y., and Cochrane, John H. "By Force Of Habit: a Consumption-Based Explanation of Aggregate Stock Market Behavior.” J.P.E. 107, (April 1999): 205-251. Carlson, John A. and Osler, Carol, L. "Short-run Exchange-rate Dynamics: Theory and Evidence.” Mimeo, (December 2005).

Chari, V.V., Kehoe, Patrick J. and McGrattan, Ellen R. "Can Sticky Price Models Generate Volatile and Persistent Real Exchange Rates?” R. E. Studs. 69 (July 2002): 533-563.

Chetty, Raj and Adam Szeidl. "Consumption Commitments: Neoclassical Foundations for Habit Formation", (October 2005), available at http://emlab.berkeley.edu/users/chetty/papers/habit.pdf Chinn, Menzie and Meredith, Guy. "Monetary Policy and Long-Horizon Uncovered Interest Parity." IMF Staff Papers 51, (2004):409-430. 
Chinn, Menzie. "The (Partial) Rehabilitation of Interest Rate Parity in the Floating Rate Era: Longer Horizons, Alternative Expectations, and Emerging Markets." Journal of International Money and Finance 25, (February 2006):7-21.

Christiano, Laurence J. "Modelling the Liquidity Effect of a Money Shock.” Federal Reserve Bank of Minneapolis Quarterly Review (Winter 1991): 3-34.

Constantinides, G. "Habit Formation: A Resolution of the Equity Premium Puzzle" Journal of Political Economy 98: (1990): 519-543.

Crossley, Thomas F., and Low, Hamish W., (2008). Is the Elasticity of Intertemporal Substitution Constant?. Journal of the European Economics Association, forthcoming.

Duesenberry, J. S., Income, Saving and the Theory of Consumer Behavior. Cambridge, Mass.: Harvard Univ. Press, 1949.

Elliott, Graham, "On the Robustness of Cointegration Methods when Regressors Almost Have Unit Roots, Econometrica 66: (January, 1998):149-158.

Engel, Charles, "On the Foreign Exchange Risk Premium in a General Equilibrium Model”, J. of Internat. Econ. 32, (1992): 305-319.

Engel, Charles. "The Forward Discount Anomaly and the Risk Premium: a Survey of Recent Evidence.” Journal of Empirical Finance 3, (June, 1996): 123-191.

Engel, Charles, "On the Foreign Exchange Risk Premium in Sticky-Price General Equilibrium Models," International Tax and Public Finance 6, (November 1999): 491-505.

Engel, Charles, “Comments on Obstfeld and Rogoff's 'The Six Major Puzzles in International Macroeconomics: Is there a Common Cause?"” NBER Macroeconomics Annual, 15, Cambridge Mass: MIT Press, 2001. 
Evans, Martin D. D. and Lyons, Richard K., "Order Flow and Exchange Rate Dynamics”, J.P.E. 110, (February, 2002): 170-180.

Evans, Martin D. D. and Lyons, Richard K., “A New Micro Model of Exchange Rate Dynamics", (2005). An earlier version is available as NBER Working Paper 10379, (March 2004).

Feenstra, Robert C. "Functional Equivalence Between Liquidity Costs and the Utility of Money," Journal of Monetary Economics 17: (1986): 271-291.

Faust, Jon, Rogers, John H. and Wright, Jonathan H., "Exchange Rate Forecasting: the Errors We’ve Really Made” J. Int. Econ. 60, (May 2003): 35-59.

Fisher, Eric O’N. “The Forward Premium in a Model with Heterogeneous Prior Beliefs.” Journal of International Money and Finance 25, (February 2006):48-70.

Flood, Robert P. and Rose, Andrew K., "Understanding Exchange Rate Volatility without the Contrivance of Macroeconomics.” Economic Journal 109, (1999): 660-672.

Frankel, Jeffrey and Poonawala, Jumana. "The Forward Market in Emerging Currencies: Less Biased than in Major Currencies." mimeo Kennedy School of Government, Harvard University, (September, 2004).

Gourinchas, Pierre-Olivier and Tornell, Aaron. "Exchange Rate Puzzles and Distorted Beliefs." J. Int. Econ. 64, (March 2004): 303-333.

Gourinchas, Pierre-Olivier, and Parker, Jonathan A., (2002). Consumption over the Life Cycle. Econometrica 70, 47-89.

Hau, Harald, "Competitive Entry and Endogenous Risk in the Foreign Exchange Market." Review of Financial Studies 11, (Winter 1998): 757-788. 
Hodrick, Robert J. "The Empirical Evidence on the Efficiency of Forward and Futures Foreign Exchange Markets." Switzerland: Harwood Academic Publishers, 1987.

Jeanne, Olivier. and Rose Andrew K., "Noise trading and exchange rate regimes", Quarterly Journal of Economics 117, (May 2002): 537-569.

Killeen, William P, Richard K. Lyons, and Moore Michael, "Fixed versus Flexible: lessons from EMS order flow", forthcoming in the Journal of International Money and Finance 2006. An earlier version is available as NBER working paper 8491, (August 2001).

Ljungqvist, Lars and Uhlig, Harald, "Tax Policy and Aggregate Demand Management under Catching up with the Joneses.” A.E.R. 90, (June 2000): 356-366.

Lucas, Robert E. "Interest Rates and Currency Prices in a Two-country World." J. Monetary Econ. 10, (November 1982): 335-360.

Mark, Nelson, "Exchange rates and Fluctuations: Evidence on Long-Horizon Predictability." A.E.R. 85, (March 1995): 201-218.

Meese, Richard A. and Rogoff, Kenneth. "Empirical Exchange Rate Models of the Seventies, Do They Fit Out of Sample?.” J. of Internat. Econ. 14, (February 1983): 3-24.

Moore, Michael J. "Covered Purchasing Power Parity, Ex-Ante PPP and Risk Aversion." Journal of Business Finance and Accounting 24, (April, 1997): 397-412.

Moore, Michael J. and Roche, Maurice J. "Less of a Puzzle: a New Look at the Forward Forex Market.” J. of Internat. Econ. 58 (December 2002): 387-411.

Moore, Michael J. and Roche, Maurice J. "A neo-classical explanation of nominal exchange rate volatility" in Exchange Rate Economics: Where do we stand? edited by Paul de Grauwe, MIT Press, 2005. 
Moore, Michael J. and Roche, Maurice J. "Volatile and Persistent Real Exchange Rates with or without Sticky Prices”, Journal of Monetary Economics, (February 2007) forthcoming.

Obstfeld, M., Rogoff, K.S., 2000. New Directions for Stochastic Open Economy Models.

Journal of International Economics 50, 117-153.

Obstfeld, Maurice and Rogoff, Kenneth. "The Six Major Puzzles in International

Macroeconomics: Is there a Common Cause?" NBER Macroeconomics Annual, 15, Cambridge

Mass: MIT Press, 2001.

Oswald, Andrew J. and Clarke, Andrew E. "Satisfaction and Comparison Income." J. Public Econ. 61, (September 1996): 359-381.

Oswald, Andrew J. "Happiness and Economics.” Economic Journal 107, (November 1997): $1815-1831$.

Ravn, Morten, Schmitt-Grohe, Stephanie and Uribe, Martin. "Deep Habits." Review of Economic Studies 73, (January 2006): 195-218.

Ravn, Morten, Schmitt-Grohe, Stephanie and Uribe, Martin, (2007). Pricing of Habits and the law of One Price. American Economic Review 73, 195-218.

Sarno, Lucio "Towards a Solution to the Puzzles in Exchange Rate Economics: Where Do We Stand?" Canadian Journal of Economics 38, (August, 2005): 673-708.

Taylor, Mark. "The Economics of Exchange Rates.” Journal of Economic Literature 33, (March, 1995): 13-47.

Verdelhan, Adrien. “A Habit-Based Explanation of the Exchange Rate Risk Premium.” Mimeo Boston University, (June 2007). 
Table 1

Average relative RMSE of the monetary model in out-of-sample forecasting in the data

$\begin{array}{cc}\text { Forecast Horizon } k & \\ 1 & 1.000 \\ 4 & 0.955 \\ 8 & 1.133 \\ 12 & 1.338 \\ 16 & 1.495\end{array}$

Note to the table: These results are the average taken from Table 1 in Faust, Rogers and Wright (2003). The entries in the table show the ratio of the out-of-sample RMSE from the monetary model to that of the driftless random walk model using real-time data. The exchange rates are versus the U.S. dollar. 
Table 2

Properties of forward and spot exchange rates in the data

\begin{tabular}{lccccccccc}
\hline & CAD/ & GBP/ & JPY/ & CHF/ & EUR/ & CAD/ & GBP/ & JPY/ & CHF/ \\
& USD & USD & USD & USD & USD & EUR & EUR & EUR & EUR \\
\cline { 2 - 9 } & -0.48 & -1.23 & -2.61 & -1.68 & -0.55 & -0.33 & -0.24 & -1.61 & -0.63 \\
Point estimate of $b_{1}$ & -0.11 & -1.11 & -3.51 & -1.32 & -0.44 & -0.17 & -0.13 & -0.91 & -0.03 \\
Covariance \% & & & & & & & & & \\
& & & & & & & & \\
$\quad$ Volatility \% & 2.51 & 5.19 & 6.25 & 6.68 & 6.28 & 6.51 & 4.72 & 5.54 & 2.10 \\
Spot return & 0.63 & 1.50 & 2.44 & 1.80 & 1.19 & 0.89 & 0.88 & 1.35 & 0.36 \\
Expected forward profit & 0.20 & 0.83 & 1.76 & 1.13 & 0.42 & 0.22 & 0.17 & 0.83 & 0.14 \\
Expected spot return & 0.43 & 0.67 & 0.67 & 0.67 & 0.76 & 0.67 & 0.70 & 0.51 & 0.22 \\
Forward discount & & & & & & & & & \\
$\quad$ Persistence & & & & & & & & & \\
Spot return & 0.07 & 0.13 & 0.10 & 0.03 & 0.06 & 0.07 & 0.06 & 0.14 & -0.03 \\
Forward discount & 0.74 & 0.78 & 0.77 & 0.93 & 0.87 & 0.89 & 0.89 & 0.82 & 0.62 \\
\hline
\end{tabular}

Notes to the table: The data were obtained from Datastream International. The sample period for Canadian dollar, British pound, Japanese yen and euro spot exchange rates is 1973:1-2005:4. The sample period for the Canadian dollar, British pound and euro forward exchange rates is 1976:2-2005:4. The sample period for the Japanese yen forward exchange rates is 1978:3-2004:4. The sample period of the Swiss franc spot and forward exchange rates is 1984:1-2005:4. The deutschmark is used to proxy for the euro prior to 1999:1. The coefficient $b_{1}$ is estimated from regressing the spot return on the lagged forward premium. The covariance is between the expected forward profit and the expected spot return. The expected forward profit is calculated as the fitted value from regressing realized forward profits on the lagged forward premium. The expected spot return is calculated as the fitted value from regressing realized spot returns on the lagged forward premium. 
Table 3

Baseline parameterization

$\begin{array}{cc}\text { Consumption growth } & \text { Money growth } \\ 0.4725 & 1.36 \\ 0.00 & 0.1 \\ 0.75 & 0.946\end{array}$

\section{Other parameters}

Discount factor $\beta$

0.99

Curvature of the utility function $\gamma$

0.5

AR1 coefficient of log surplus consumption $\phi$

0.999

Parameter in steady state surplus consumption $\delta$

$-0.005$




\section{Table 4}

Relative RMSE of the monetary model in out-of-sample forecasting in the theoretical economy

\begin{tabular}{cccccc}
\hline & Baseline & $\gamma=0.7$ & $\delta=-0.0025$ & $\rho_{\pi}=0$ & $\phi=0.995$ \\
\cline { 2 - 6 } Forecast Horizon $k$ & & & & \\
1 & 1.02 & 1.03 & 1.02 & 1.03 & 1.02 \\
& $(0.002)$ & $(0.002)$ & $(0.002)$ & $(0.002)$ & $(0.003)$ \\
4 & 1.09 & 1.09 & 1.07 & 1.10 & 1.07 \\
& $(0.007)$ & $(0.007)$ & $(0.005)$ & $(0.007)$ & $(0.008)$ \\
& 1.18 & 1.18 & 1.15 & 1.19 & 1.14 \\
12 & $(0.015)$ & $(0.015)$ & $(0.011)$ & $(0.015)$ & $(0.014)$ \\
& 1.27 & 1.28 & 1.24 & 1.28 & 1.21 \\
16 & $(0.023)$ & $(0.025)$ & $(0.019)$ & $(0.024)$ & $(0.020)$ \\
& 1.36 & 1.38 & 1.33 & 1.37 & 1.29 \\
& $(0.029)$ & $(0.033)$ & $(0.026)$ & $(0.030)$ & $(0.028)$ \\
\hline
\end{tabular}

Notes to the table: The mean and standard deviation (in parenthesis) of the statistic is based on 1000 simulations of 132 observations. 
Table 5

Percentage number of rejections

\begin{tabular}{lccccc}
\hline & Baseline & $\gamma=0.7$ & $\delta=-0.0025$ & $\rho_{\pi}=0$ & $\phi=0.995$ \\
\cline { 2 - 6 }$z_{t}$ unit root test & 20.70 & 15.20 & 14.80 & 20.70 & 27.20 \\
$\hat{e}_{t}$ unit root test & 45.40 & 35.40 & 36.20 & 45.20 & 37.40 \\
Wald test & 71.80 & 80.70 & 81.20 & 72.00 & 76.20 \\
\hline
\end{tabular}

Notes to the table: The results are based on 1000 simulations of 132 observations.

We define $z_{t}$ as $-\left(y_{t}^{1}-y_{t}^{2}\right)+\left(m_{t}^{1}-m_{t}^{2}\right)-s_{t}$. The residuals $\hat{e}_{t}$ are obtained by estimating $s_{t}=\alpha_{0}+\alpha_{1}\left(y_{t}^{1}-y_{t}^{2}\right)+\alpha_{2}\left(m_{t}^{1}-m_{t}^{2}\right)+e_{t}$ by FM-OLS. The unit root test is an augmented Dickey-Fuller test where the lag length in the test regression is chosen by reduction methods. The Wald test is a test of the joint null hypothesis $\mathrm{H}_{0}: \alpha_{1}=\gamma-1$ and $\alpha_{2}=1$. 
Table 6

Properties of exchange rates and consumer price indices in Hodrick-Prescott filtered data in the theoretical economy

\begin{tabular}{|c|c|c|c|c|c|}
\hline \multirow{2}{*}{\multicolumn{6}{|c|}{ Volatility \% }} \\
\hline & & & & & \\
\hline l exchange rate & $\begin{array}{l}7.98 \\
(0.290)\end{array}$ & $\begin{array}{l}9.28 \\
(0.256)\end{array}$ & $\begin{array}{l}6.77 \\
(0.180)\end{array}$ & $\begin{array}{l}7.91 \\
(0.291)\end{array}$ & $\begin{array}{l}10.57 \\
(0.293)\end{array}$ \\
\hline of trade & $\begin{array}{l}7.90 \\
(0.308)\end{array}$ & $\begin{array}{l}9.65 \\
(0.269)\end{array}$ & $\begin{array}{l}6.95 \\
(0.197)\end{array}$ & $\begin{array}{l}7.90 \\
(0.308)\end{array}$ & $\begin{array}{l}11.02 \\
(0.302)\end{array}$ \\
\hline
\end{tabular}

\section{Persistence}

Nominal exchange rate

$\begin{array}{lcccc}0.70 & 0.69 & 0.70 & 0.68 & 0.68 \\ (0.003) & (0.003) & (0.003) & (0.003) & (0.003) \\ 0.66 & 0.67 & 0.67 & 0.66 & 0.67 \\ (0.003) & (0.003) & (0.003) & (0.003) & (0.003)\end{array}$

Cross-correlations

Terms of trade and

0.76

0.65

0.55

0.89

nominal exchange rate

$(0.015)$

(0.010)

$(0.013)$

(0.015)

(0.005)

Notes to the table: The mean and standard deviation (in parenthesis) of the statistic is based on 1000 simulations of 132 observations. 


\section{Table 7}

Properties of exchange rates and consumer price indices in first-differenced data in the theoretical economy

\begin{tabular}{lccccc} 
& Baseline & $\gamma=0.7$ & $\delta=-0.0025$ & $\rho_{\pi}=0$ & $\phi=0.995$ \\
\cline { 2 - 6 } Volatility \% & \multicolumn{5}{c}{} \\
Mnal exchange rate & 6.36 & 7.42 & 5.38 & 6.36 & 8.48 \\
& $(0.232)$ & $(0.203)$ & $(0.143)$ & $(0.232)$ & $(0.233)$ \\
s of trade & 6.37 & 7.79 & 5.59 & 6.37 & 8.89 \\
& $(0.245)$ & $(0.212)$ & $(0.155)$ & $(0.245)$ & $(0.239)$
\end{tabular}

\section{Persistence}

Nominal exchange rate

$\begin{array}{lllll}0.02 & 0.01 & 0.02 & -0.02 & -0.01 \\ (0.004) & (0.004) & (0.004) & (0.004) & (0.004) \\ -0.03 & -0.02 & -0.02 & -0.04 & -0.02 \\ (0.004) & (0.004) & (0.004) & (0.004) & (0.004)\end{array}$

Cross-correlations

Terms of trade and

$0.58 \quad 0.78$

0.67

0.58

0.91

nominal exchange rate

(0.014)

(0.009)

$(0.012)$

$(0.014)$

$(0.004)$

Notes to the table: The mean and standard deviation (in parenthesis) of the statistic is based on 1000 simulations of 132 observations. 
Table 8

Properties of forward and spot exchange rates in the theoretical economy

\begin{tabular}{lclccc}
\hline & Baseline & $\gamma=0.7$ & $\delta=-0.0025$ & $\rho_{\pi}=0$ & $\phi=0.995$ \\
\cline { 2 - 6 } \% of negative slope coefficients & 55.30 & 66.80 & 56.50 & 92.30 & 78.70 \\
$\%$ of negative covariances & 79.10 & 83.80 & 80.80 & 99.00 & 90.90 \\
Point estimate of $b_{1}$ & -1.08 & -1.99 & -1.34 & -27.95 & -2.43 \\
& $(0.089)$ & $(0.110)$ & $(0.110)$ & $(2.188)$ & $(0.100)$ \\
Covariance \% & -2.31 & -2.03 & -0.78 & -2.60 & -3.28 \\
& $(0.198)$ & $(0.144)$ & $(0.064)$ & $(0.204)$ & $(0.239)$
\end{tabular}

\section{Volatility \%}

Spot return

$\begin{array}{ccccc}6.36 & 7.42 & 5.38 & 6.36 & 8.48 \\ (0.232) & (0.203) & (0.143) & (0.232) & (0.233)\end{array}$

Expected forward profit

$\begin{array}{ll}0.97 & 1.02 \\ (0.045) & (0.038)\end{array}$

0.59

1.15

1.35

0.78

0.84

$(0.024)$

$(0.044)$

$(0.048)$

Expected spot return

(0.036)

(0.032)

0.51

0.95

1.07

Forward discount

$\begin{array}{lllll}0.30 & 0.26 & 0.18 & 0.22 & 0.34 \\ (0.010) & (0.006) & (0.003) & (0.011) & (0.010)\end{array}$

\section{Persistence}

Spot return

$\begin{array}{lccll}0.02 & 0.01 & 0.02 & -0.02 & -0.01 \\ (0.004) & (0.004) & (0.004) & (0.004) & (0.004)\end{array}$

Forward discount

$\begin{array}{ccc}0.40 & 0.46 & 0.33 \\ (0.011) & (0.011) & (0.009)\end{array}$

0.82

0.51

Notes to the table: The mean and standard deviation (in parenthesis) of the statistic is based on 1000 simulations of 132 observations. 


\section{Appendix A1: Solving the Optimization Problem}

The level of endowment or output for the domestic (foreign) country is assumed to

be $2 Y_{t}^{1}\left(2 Y_{t}^{2}\right)$. Since the markets are assumed to be complete as in Lucas (1982), households' share risk and so consumption of domestic and foreign goods of all households is $Y_{t}^{1}$ and $Y_{t}^{2}$.

From the first order $^{17}$ conditions ${ }^{18}$, we can solve for the terms of trade:

$$
R_{t}=\frac{S_{t} P_{t}^{2}}{P_{t}^{1}}=\frac{\left(C_{t}^{2} X_{t}^{2}\right)^{-\gamma}}{\left(C_{t}^{1} X_{t}^{1}\right)^{-\gamma}}=\frac{\left(Y_{t}^{2} X_{t}^{2}\right)^{-\gamma}}{\left(Y_{t}^{1} X_{t}^{1}\right)^{-\gamma}}
$$

From the households' choice of state contingent bonds, we may define a risk-free nominal

bond price in domestic currency:

$$
q_{t}^{1}=\sum_{\tau_{t+1} \in \mathrm{T}} Q^{1}\left(\tau_{t+1}, \tau_{t}\right)=\beta E_{t}\left[\frac{\left(C_{t+1}^{1} X_{t+1}^{1}\right)^{-\gamma}}{\left(C_{t}^{1} X_{t}^{1}\right)^{-\gamma}} \frac{P_{t}^{1}}{P_{t+1}^{1}}\right]=\beta E_{t}\left[\frac{\left(Y_{t+1}^{1} X_{t+1}^{1}\right)^{-\gamma}}{\left(Y_{t}^{1} X_{t}^{1}\right)^{-\gamma}} \frac{P_{t}^{1}}{P_{t+1}^{1}}\right]
$$

Similarly, the risk-free nominal bond price in foreign currency is :

$$
q_{t}^{2}=\sum_{\tau_{t+1} \in \mathrm{T}} Q^{2}\left(\tau_{t+1}, \tau_{t}\right)=\beta E_{t}\left[\frac{\left(C_{t+1}^{2} X_{t+1}^{2}\right)^{-\gamma}}{\left(C_{t}^{2} X_{t}^{2}\right)^{-\gamma}} \frac{P_{t}^{2}}{P_{t+1}^{2}}\right]=\beta E_{t}\left[\frac{\left(Y_{t+1}^{2} X_{t+1}^{2}\right)^{-\gamma}}{\left(Y_{t}^{2} X_{t}^{2}\right)^{-\gamma}} \frac{P_{t}^{2}}{P_{t+1}^{2}}\right]
$$

Using the cash in advance constraints (8) we can factor out prices to express the nominal exchange rate (A1) as:

$$
S_{t}=\frac{\left(Y_{t}^{2} X_{t}^{2}\right)^{-\gamma}}{\left(Y_{t}^{1} X_{t}^{1}\right)^{-\gamma}} \frac{P_{t}^{1}}{P_{t}^{2}}=\frac{\left(Y_{t}^{2}\right)^{1-\gamma}\left(X_{t}^{2}\right)^{-\gamma}}{\left(Y_{t}^{1}\right)^{1-\gamma}\left(X_{t}^{1}\right)^{-\gamma}} \frac{M_{t}^{1}}{M_{t}^{2}}
$$

\footnotetext{
${ }^{17}$ It is easy to show that the problem is a reparameterisation of the fuller problem that either includes the two cash in advance constraints (8) or replaces consumption with money as the control variable. Money is reintroduced later by replacing prices with their values implied by the cash in advance constraints.

${ }^{18}$ Recall that the habit is external. This idea is implemented by treating the surplus consumption ratio as exogenous in the optimization problem.
} 


\section{Appendix A2: The Terms of Trade and Nominal Exchange Rates}

Taking logged first differences of (A4) the spot return is:

$$
s_{t+1}-s_{t}=-(1-\gamma)\left(\Delta y_{t+1}^{1}-\Delta y_{t+1}^{2}\right)+\gamma\left(\Delta x_{t+1}^{1}-\Delta x_{t+1}^{2}\right)+\left(\Delta m_{t+1}^{1}-\Delta m_{t+1}^{2}\right)
$$

Equation (A5) can be written as:

$$
\begin{aligned}
s_{t+1}-s_{t}= & \left(\Delta m_{t+1}^{1}-\Delta m_{t+1}^{2}\right)-(1-\gamma)\left(v_{t+1}^{1}-v_{t+1}^{2}\right) \\
& -\gamma(1-\phi)\left(x_{t}^{1}-x_{t}^{2}\right)+\gamma\left(\lambda\left(x_{t}^{1}\right) v_{t+1}^{1}-\lambda\left(x_{t}^{2}\right) v_{t+1}^{2}\right) \\
= & \left(\Delta m_{t+1}^{1}-\Delta m_{t+1}^{2}\right)-\gamma(1-\phi)\left(x_{t}^{1}-x_{t}^{2}\right) \\
& -\left(1-\gamma\left(1+\lambda\left(x_{t}^{1}\right)\right)\right) v_{t+1}^{1}+\left(1-\gamma\left(1+\lambda\left(x_{t}^{2}\right)\right)\right) v_{t+1}^{2}
\end{aligned}
$$

from which, we have:

$$
\operatorname{Var}\left(s_{t+1}-s_{t}\right)=2\left(\frac{\sigma_{u}^{2}}{1-\rho_{\pi}^{2}}+(1-\phi)^{2} \gamma^{2} \sigma_{x}^{2}+\sigma_{v}^{2}\left(1-\frac{\gamma}{\bar{X}}\right)^{2}\right)
$$

The last expression is obtained from the fact that:

$$
E\left(1+\lambda\left(x_{t}^{j}\right)\right)=\frac{1}{\bar{X}} \quad \text { and } \quad E\left(1+\lambda\left(x_{t}^{j}\right)\right)^{2}=\frac{1}{\bar{X}^{2}}
$$

Similarly, taking logged first differences of (A1), the change in the terms of trade is:

$$
r_{t+1}-r_{t}=\gamma\left(\Delta y_{t+1}^{1}-\Delta y_{t+1}^{2}\right)+\gamma\left(\Delta x_{t+1}^{1}-\Delta x_{t+1}^{2}\right)
$$

from which, we have:

$$
\operatorname{Var}\left(r_{t+1}-r_{t}\right)=2\left((1-\phi)^{2} \gamma^{2} \sigma_{x}^{2}+\sigma_{v}^{2}\left(\frac{\gamma}{\bar{X}}\right)^{2}\right)
$$




\section{Appendix A3: Expressions for the Forward Premium, Expected Spot Return and Expected Forward Profit}

The domestic and foreign nominal interest rates are obtained easily. Using the cash in advance constraints (8) we obtain from (A2) and (A3):

$$
q_{t}^{j}=\beta E_{t}\left[\left(\frac{Y_{t+1}^{j}}{Y_{t}^{j}}\right)^{1-\gamma}\left(\frac{X_{t+1}^{j}}{X_{t}^{j}}\right)^{-\gamma}\left(\frac{M_{t+1}^{j}}{M_{t}^{j}}\right)^{-1}\right]
$$

This yields:

$$
\begin{aligned}
\ln q_{t}^{j} & =\ln E_{t}\left[\beta e^{\left\{(1-\gamma)\left(\bar{\mu}+v_{t+1}^{j}\right)-\gamma\left((\phi-1)\left(x_{t}^{j}-\bar{x}\right)+\lambda\left(x_{t}^{j}\right) v_{t+1}^{j}\right)-\left(\left(1-\rho_{\pi}\right) \bar{\pi}+\rho_{\pi} \Delta m_{t}^{j}+u_{t+1}^{j}\right)\right\}}\right] \\
& =\ln E_{t}\left[\beta e^{\left\{(1-\gamma) \bar{\mu}-\left(\left(1-\rho_{\pi}\right) \bar{\pi}+\rho_{\pi} \Delta m_{t}^{j}\right)-\gamma\left((\phi-1)\left(x_{t}^{j}-\bar{x}\right)\right)+v_{t+1}^{j}-\gamma\left(1+\lambda\left(x_{t}^{j}\right)\right) v_{t+1}^{j}-u_{t+1}^{j}\right\}}\right]
\end{aligned}
$$

Using the properties of the lognormal distribution on (A12):

$$
\begin{aligned}
\ln q_{t}^{j}= & \ln \beta-\gamma \bar{\mu}-\gamma\left((\phi-1)\left(x_{t}^{j}-\bar{x}\right)\right)+\frac{1}{2} \gamma^{2}\left(\frac{1-2\left(\left(x_{t}^{j}-\bar{x}\right)\right)}{\bar{X}^{2}}\right) \sigma_{v}^{2} \\
& +\bar{\mu}-\left(\left(1-\rho_{\pi}\right) \bar{\pi}+\rho_{\pi} \Delta m_{t}^{j}\right)+\frac{1}{2}\left(1-2 \gamma\left(1+\lambda\left(x_{t}^{j}\right)\right)\right) \sigma_{v}^{2}+\frac{1}{2} \sigma_{u}^{2}
\end{aligned}
$$

The first line in equation (A13) represents the real bond price which is the negative of the expression for the log real risk free interest rate in Campbell and Cochrane (1999). A firstorder Taylor series expansion to the square root function (11) around the steady state given by (12) is:

$$
\frac{\sqrt{1-2\left(x_{t}^{j}-\bar{x}\right)}}{\bar{X}}=\lambda\left(x_{t}^{j}\right)+1 \approx \frac{1}{\bar{X}}-\frac{1}{\bar{X}}\left(x_{t}^{j}-\bar{x}\right) \quad j=1,2
$$

Using equation (12) and (A14) in (A13) gives the following expression for log bond prices:

$$
\begin{aligned}
\ln q_{t}^{j} & =\ln \beta-\gamma \bar{\mu}+\frac{1}{2}(\gamma(1-\phi)-\delta)+\delta\left(x_{t}^{j}-\bar{x}^{j}\right) \\
& +\bar{\mu}-\left(1-\rho_{\pi}\right) \bar{\pi}+\frac{1}{2}\left(\sigma_{v}^{2}\left(1-\frac{2 \gamma}{\bar{X}}\right)+\sigma_{u}^{2}\right)-\rho_{\pi} \Delta m_{t}^{j}+\left(\frac{\bar{X}}{\gamma}(\gamma(1-\phi)-\delta)\right)\left(x_{t}^{j}-\bar{x}^{j}\right)
\end{aligned}
$$

Equation (A15) can be simplified to: 


$$
\begin{aligned}
\ln q_{t}^{j} & =-\alpha-\rho_{\pi} \Delta m_{t}^{j}+\left(\delta+\frac{\bar{X}}{\gamma}(\gamma(1-\phi)-\delta)\right)\left(x_{t}^{j}-\bar{x}^{j}\right) \\
& =-\alpha-\rho_{\pi} \Delta m_{t}^{j}+\left(\delta+\sigma_{v} \sqrt{\gamma(1-\phi)-\delta}\right)\left(x_{t}^{j}-\bar{x}^{j}\right) \\
& =-\alpha-\rho_{\pi} \Delta m_{t}^{j}-\theta\left(x_{t}^{j}-\bar{x}^{j}\right)
\end{aligned}
$$

where the constant, $\alpha$, is given by:

$$
\alpha=-\left[\ln \beta+(1-\gamma) \bar{\mu}-\left(1-\rho_{\pi}\right) \bar{\pi}+\frac{1}{2}\left(\gamma(1-\phi)-\delta+\sigma_{v}^{2}\left(1-\frac{2 \gamma}{\bar{X}}\right)+\sigma_{u}^{2}\right)\right]
$$

and the parameter governing the sensitivity of nominal bond prices, $\theta$, to the surplus consumption ratio is:

$$
\theta=-\left[\delta+\sigma_{\nu} \sqrt{\gamma(1-\phi)-\delta}\right]
$$

Using (16) and (A15) the forward discount equals:

$$
\begin{aligned}
\ln \left(\frac{F_{t}}{S_{t}}\right) & =f_{t}-s_{t}=\ln q_{t}^{2}-\ln q_{t}^{1} \\
& =\rho_{\pi}\left(\Delta m_{t}^{1}-\Delta m_{t}^{2}\right)-\left(\delta+\frac{\bar{X}}{\gamma}(\gamma(1-\phi)-\delta)\right)\left(x_{t}^{1}-x_{t}^{2}\right) \\
& =\rho_{\pi}\left(\Delta m_{t}^{1}-\Delta m_{t}^{2}\right)-\left(\delta+\sigma_{v} \sqrt{\gamma(1-\phi)-\delta}\right)\left(x_{t}^{1}-x_{t}^{2}\right) \\
& =\rho_{\pi}\left(\Delta m_{t}^{1}-\Delta m_{t}^{2}\right)+\theta\left(x_{t}^{1}-x_{t}^{2}\right)
\end{aligned}
$$

Taking time $t$ conditional expectations of (A5) the expected spot return is:

$$
E_{t}\left(s_{t+1}-s_{t}\right)=-\gamma(1-\phi)\left(x_{t}^{1}-x_{t}^{2}\right)+\rho_{\pi}\left(\Delta m_{t}^{1}-\Delta m_{t}^{2}\right)
$$

The expected forward profit is obtained by subtracting (A20) from (A19): 


$$
\begin{aligned}
f_{t}-E_{t}\left(s_{t+1}\right) & =(-(\delta+\bar{X}(1-\phi-\delta / \gamma))+\gamma(1-\phi))\left(x_{t}^{1}-x_{t}^{2}\right) \\
& =(\gamma(1-\phi)-\delta)\left(1-\frac{\bar{X}}{\gamma}\right)\left(x_{t}^{1}-x_{t}^{2}\right) \\
& =\left((\gamma(1-\phi)-\delta)-\sigma_{v} \sqrt{\gamma(1-\phi)-\delta}\right)\left(x_{t}^{1}-x_{t}^{2}\right) \\
& =\left(\gamma(1-\phi)-\left\{\delta+\sigma_{v} \sqrt{\gamma(1-\phi)-\delta}\right\}\right)\left(x_{t}^{1}-x_{t}^{2}\right) \\
& =(\gamma(1-\phi)+\theta)\left(x_{t}^{1}-x_{t}^{2}\right)
\end{aligned}
$$

The coefficient on the log surplus consumption differential, $\gamma(1-\phi)+\theta$, is positive since $\gamma(1-\phi)>\delta$ and $\bar{X} / \gamma$ is less than unity because it is the inverse of the goods-specific coefficient of relative risk aversion. We assume that this is greater than one. 


\section{Appendix A4: Second Moments for the Forward Premium, Expected Spot Return and Expected Forward Profit}

Using (A20) the unconditional variance of the expected spot change is:

$$
\operatorname{Var}\left(E_{t}\left(s_{t+1}-s_{t}\right)\right)=2\left(\frac{\rho_{\pi}^{2} \sigma_{u}^{2}}{1-\rho_{\pi}^{2}}+\gamma^{2}(1-\phi)^{2} \sigma_{x}^{2}\right)
$$

Using (A19) the unconditional variance of the forward discount is:

$$
\begin{aligned}
\operatorname{Var}\left(f_{t}-s_{t}\right) & =2\left(\frac{\rho_{\pi}^{2} \sigma_{u}^{2}}{1-\rho_{\pi}^{2}}+\left(\delta+\frac{\bar{X}}{\gamma}(\gamma(1-\phi)-\delta)\right)^{2} \sigma_{x}^{2}\right) \\
& =2\left(\frac{\rho_{\pi}^{2} \sigma_{u}^{2}}{1-\rho_{\pi}^{2}}+\left(\delta+\sigma_{v} \sqrt{\gamma(1-\phi)-\delta}\right)^{2} \sigma_{x}^{2}\right) \\
& =2\left(\frac{\rho_{\pi}^{2} \sigma_{u}^{2}}{1-\rho_{\pi}^{2}}+\theta^{2} \sigma_{x}^{2}\right)
\end{aligned}
$$

Using (A21) the unconditional variance of the expected forward profit is:

$$
\begin{aligned}
\operatorname{Var}\left(f_{t}-E_{t} s_{t+1}\right) & =2\left((\gamma(1-\phi)-\delta)\left(1-\frac{\bar{X}}{\gamma}\right)\right)^{2} \sigma_{x}^{2} \\
& =2\left((\gamma(1-\phi)-\delta)-\sigma_{v} \sqrt{\gamma(1-\phi)-\delta}\right)^{2} \sigma_{x}^{2} \\
& =2\left(\gamma(1-\phi)-\left\{\delta+\sigma_{v} \sqrt{\gamma(1-\phi)-\delta}\right\}\right)^{2} \sigma_{x}^{2} \\
& =2(\gamma(1-\phi)+\theta)^{2} \sigma_{x}^{2}
\end{aligned}
$$

The covariance between expected forward profits (A21) and the expected spot return (A20) is:

$$
\begin{aligned}
\operatorname{Cov}\left[\left(f_{t}-E_{t}\left(s_{t+1}\right),\left(E_{t}\left(s_{t+1}-s_{t}\right)\right)\right)\right] & =-2 \gamma(1-\phi)(\gamma(1-\phi)-\delta)\left(1-\frac{\bar{X}}{\gamma}\right) \sigma_{x}^{2} \\
& =-2 \gamma(1-\phi)\left(\gamma(1-\phi)-\left\{\delta+\sigma_{v} \sqrt{\gamma(1-\phi)-\delta}\right\}\right) \sigma_{x}^{2}(\mathrm{~A} 25) \\
& =-2 \gamma(1-\phi)(\gamma(1-\phi)+\theta) \sigma_{x}^{2}
\end{aligned}
$$

From the remarks following (A21), we know that $\gamma(1-\phi)+\theta$ is positive and therefore the covariance (A25) is negative. 
The coefficient in the Fama regression, equation (4) is:

$$
\begin{aligned}
& \frac{\operatorname{Var} E_{t}\left(s_{t+1}-s_{t}\right)+\operatorname{Cov}\left[\left(f_{t}-E_{t}\left(s_{t+1}\right),\left(E_{t}\left(s_{t+1}-s_{t}\right)\right)\right)\right]}{\operatorname{Var}\left(f_{t}-s_{t}\right)} \\
& =\frac{2\left(\frac{\rho_{\pi}^{2} \sigma_{u}^{2}}{1-\rho_{\pi}^{2}}+\gamma^{2}(1-\phi)^{2} \sigma_{x}^{2}\right)-2 \gamma(1-\phi)\left(\gamma(1-\phi)-\left\{\delta+\sigma_{v} \sqrt{\gamma(1-\phi)-\delta}\right\}\right) \sigma_{x}^{2}}{2\left(\frac{\rho_{\pi}^{2} \sigma_{u}^{2}}{1-\rho_{\pi}^{2}}+\left(\delta+\sigma_{v} \sqrt{\gamma(1-\phi)-\delta}\right)^{2} \sigma_{x}^{2}\right)} \\
& =\frac{\frac{\rho_{\pi}^{2} \sigma_{u}^{2}}{1-\rho_{\pi}^{2}}+\gamma(1-\phi)\left\{\delta+\sigma_{v} \sqrt{\gamma(1-\phi)-\delta}\right\} \sigma_{x}^{2}}{\frac{\rho_{\pi}^{2} \sigma_{u}^{2}}{1-\rho_{\pi}^{2}}+\left(\delta+\sigma_{v} \sqrt{\gamma(1-\phi)-\delta}\right)^{2} \sigma_{x}^{2}} \\
& =\frac{\frac{\rho_{\pi}^{2} \sigma_{u}^{2}}{1-\rho_{\pi}^{2}}-\gamma(1-\phi) \theta \sigma_{x}^{2}}{\frac{\rho_{\pi}^{2} \sigma_{u}^{2}}{1-\rho_{\pi}^{2}}+\theta^{2} \sigma_{x}^{2}}
\end{aligned}
$$

